\title{
Strengthening Indonesia's Reproductive Health Education and Training System: Progress to Date
}

\author{
Abdul Bari Saifuddin*, Biran Affandi*, Djajadilaga*, Widohariadi**, Bimo ${ }^{\dagger}$, Clayton Ajello\#
}

Reproductive health concerns itself with the ability of couples to reproduce and manage their fertility in a safe and healthy manner for themselves, their newborns and already living children. ${ }^{1}$ High-quality reproductive health services promote health through prevention and management of reproductive health problems. Owing to years of sustained effort, Indonesia has made much progress in improving reproductive health services. Programs already initiated by the government of Indonesia (GOI) in conjunction with local communities have achieved significant progress which compares favorably with or is better than that of many other developing countries. For example, according to data provided to the United Nations, it is estimated that $51 \%$ of Indonesian couples of reproductive age are using contraception as compared to $45 \%$ in other developing countries and $71 \%$ in developed countries. Increasing contraceptive prevalence in turn has had a positive effect on the overall reproductive health status. Other initiatives are aimed to improve:

- antenatal care to pregnant women

- emergency obstetric services at all levels of the health care system, and

- improved operation of the health services, including the referral system

Nonetheless, satisfactory progress has not been made in making available basic, high-quality reproductive health services as is evident in Indonesia's știll high maternal mortality.

\footnotetext{
* POGI/NRC/Department of Obstetrics and Gynecology Faculty of Medicine, University of Indonesia, Jakarta, Indonesia

** POGI/NRC/Department of Obstetrics and Gynecology, University of Airlangga, Surabaya, Indonesia

† JHPIEGO/Indonesia, Jakarta, Indonesia

\# JHPIEGO Corporation, Baltimore, MD, USA
}

\section{INCREASING THE AVAILABILITY OF REPRODUCTIVE HEALTH SERVICES}

Improving the reproductive health status of Indonesian families is largely a matter of decreasing maternal mortality. Recent studies indicate that one important factor is the lack of services due to the small number health care personnel possessing the reproductive health clinical skills and knowledge needed to provide appropriate services. Lack of services, especially emergency obstetric services, is particularly acute in villages and smaller health care centers (Puskesmas).

Two interventions are central to achieving lower maternal mortality. ${ }^{2}$

- Increasing the availability and use of modern contraceptive services so that the number of high risk pregnancies wil be reduced (a long-term solution contributing to a reduction in maternal mortality).

- Increasing the availability of essential obstetric services as close to the community as is feasible (a more direct and immediate solution for reducing maternal mortality).

Basic reproductive health services in Indonesia must focus on both areas; therefore, service providers must be appropriately prepared to provide them. Moreover, if these services are to be of high quality, by definition they must be continuously available, appropriate, comprehensive and affordable. An important aspect of quality service availability is ensuring that health professionals (especially doctors and midwives) are competent in required reproductive health clinical skills and knowledge. The Core Curriculum of Medical Education in Indonesia (KIPDI, 1983), and the National Curriculum for Medical Education (KURNAS DIKDOKDI, 1994) clearly state those reproductive health competencies required by graduates. ${ }^{3}$ Similarly, the Midwifery Syllabus, Midwives Education Program relates reproductive health competencies required by midwifery graduates in Indonesia. In each case these requirements are consistent those com- 
petencies needed to perform the essential obstetric functions recommended by WHO, including family planning.

So then, why is maternal mortality still a problem in Indonesia today? A part of the answer is that despite appropriate competencies being required of key health care providers, it seems that many clinicians do not actually possess them. For example, a1992 assessment undertaken by POGI, at the request of BKKBN, indicated that only $20 \%$ of graduated doctors and midwives have the requisite skills to provide IUD and Norplant implant services. Other information in the report suggests that skills related to essential obstetric functions are similarly deficient among graduates. ${ }^{3}$

Key factors underlying this situation are that:

- Preservice medical and midwifery education stress information transfer and are less able to transfer skills.

- Available training materials often are not consistent with a competency-based training (CBT) approach. As a result, observation by learners is more common during clinical experiences than hands-on practice.

- Most reproductive health clinical training is done without the availability of uniformly accepted service delivery standards, the availability of which is an essential requirement of CBT. This situation is due to the lack of coordination of the many public and private sector agencies that implement training.

- Clinics used as clinical training sites frequently are not prepared to fulfill this role(i.e., services are not uniformly standardized and trainers have not been prepared in the clinical training skills needed to implement CBT).

The net result is that the education and training system is unable to generate and maintain a regular supply of qualified reproductive health service providers and trainers to meet national neeeds.

\section{STRENGTHENING REPRODUCTIVE HEALTH TRAINING}

\section{The Proposed Intervention}

To correct these deficiencies, in 1992 POGI recommended to the GOI that a major effort be undertaken to strengthen Indonesia's reproductive health education and training system, especially the training portion which aims to transfer practical skills and knowledge to learners in both preservice and inservice settings. A key intervention proposed at that time was to expand the application of a CBT approach throughout a unified clinical training network. ${ }^{4}$ The aim of this effort is twofold:

- to bring about an immediate and long-term increase in the numbers of graduates (from both pre- and inservice programs) competent to provide selected reproductive health services, and

- to create a sustainable capacity for maintaining an adequate supply of clinical and advanced trainers qualified in CBT as applied to reproductive health services.

\section{The Model for Change ${ }^{5}$}

To achieve incorporation of CBT into clinical training, POGI proposed the development of a unified, standardized, and supervised national clinical training network. This network would be developed from among existing, operating clinical training facilities and would concern itself initially with clinical training for family planning. Once a "system" for applying CBT to one area of reproductive health was mastered by a core group of trainers, the CBT approach would be expanded to other areas of reproductive health. To facilitate change throughout the clinical training network, POGI also proposed implementation of a training network which created specific roles for and collaborative relationships among various institutions within the network. The primary roles and tasks at each level include the following:

National Resource Center (NRC), which consists of two model service delivery and clinical training sites, will:

* guide the process of developing nationally agreed upon reproductive health service guidelines,

* develop training materials,

* prepare clinical and advanced trainers, and

* devise and develop a system of follow up and supervision in order to maintain the quality of the clinical training network.

Provincial Clinical Training Centers (PTCs) will:

* standardize district level trainers in clinical skills,

* train district level trainers in clinical training skills,

* carry out clinical training for doctors and midwives from the district level, and

* provide follow up/supervision of training at the district level

District Clinical Training Centers (DTCs) will:

* carry out clinical training for doctors and midwives from Puskesmas, and

* supervise service delivery 
Pending implementation of this plan, the need for further strengthening of Puskesmas health centers as training sites would be re-assessed. (NB. The term "clinical training network" as used here does not imply that there is a need to form a special body or new structure. Existing BKKBN training centers [Pusdiklat] and the DepKes training centers [Bapelkes] are intended to be used as the infrastructure of this training network).

\section{Timetable for Change}

POGI proposed implementation of this model in a phased manner over a 5 year period. The first step was identification and preparation of the NRC to initiate activities and become a resource for other levels of the clinical training network. Key preparatory and implementation activities at NRC clinical sites during the first phase included:

- Minor refurbishment so that services could be offered according to national service delivery guidelines.

- Standardization of NRC clinical staff providing services so that services would be offered proficiently, according to national service delivery guidelines.

- Preparation of selected, proficient service providers in clinical training skills, including strengthening their ability to conduct practice "service provider" courses.

- Preparation of selected, proficient clinical trainers in advanced training skills.

The first three of the above activities, after being completed at the NRC is then repeated at the PTC level using NRC staff as a technical resource for the PTCs.

Subsequent steps proposed included using the PTC staff as a technical resource to repeat these steps at the DTCs. In addition, to shorten the time for developing a unified clinical training network, POGI proposed that training activities done at one level of the network overlap with human resources from other levels of the network. For example, if NRC staff are participating in a training course to learn new training skills, when they practice their training skills, course participants would be selected from among PTC staff.

\section{Progress to Date}

Since 1992, much progress has been achieved in realizing a unified and standardized clinical training net- work. Moreover, the network is beginning to serve the clinical training needs (in reproductive health) of both preservice education and inservice training programs for all categories of clinical service providers. Successes to date have given rise to the expectation that this model can now begin to be extended to other areas of reproductive health education and training (e.g., essential obstetrical functions). Specific progress to date includes:

\section{Refresher Training package for Norplant ${ }^{R}$ Implants/ IUDs/Infection Prevention (referred to as NIIP Refresher Training) Developed and Launched}

In order to bring about an immediate increase in service providers skilled in the delivery of selected clinical family planning services, POGI and NRC staff with assistance from JHPIEGO developed the first training materials for clinical family planning available in Indonesia which are consistent with CBT. Developemnt of this package and implementation of refresher courses has been used as a vehicle for introducing core NRC staff to CBT and sensitizing PTC level staff to CBT.

This activity was lead by master trainers from the Ob/Gyn Departments of the Faculties of Medicine of the University of Indonesia (Klinik Raden Saleh/Dr. Cipto Mangunkusumo Hospital) and the University of Airlangga (Dr. Soetomo Hopital). Technical assistance was provided by JHPIEGO.

To date approximately 1000 service providers have participated in the NIIP Refresher Course and are now qualified and practicing these new skills. This initiative has also served to establish two models:

- one for the development of all new courses in reproductive health which might be developed in the future, and

- one for a process of disseminating new courses through the network which depends upon "tiered" implementation (i.e., NRC staff train or act as a resource to PTC staff and trainers, and PTC staff train or act as a resource for DH staff and trainers).

\section{National Resource Document Completed}

POGI in collaboration with many groups inside of Indonesia and with assistance from JHPIEGO completed a National Resource Document for family planning services which can now be used as the standardized resource for development of training materials, evaluation activities and program policy. ${ }^{6}$ 


\section{NRC Activation}

The NRC has been activated by POGI as a follow up of the 1993 cooperative agreement between BKKBN and POGI and a Steering Committee formed by a Ministerial Decree with membership from $\mathrm{MOH}, \mathrm{BKKBN}$, CHS, POGI, PKMI, IBI, and other groups. A Steering Committee has been established at each NRC under the Dean of FKUI/FKUNAIR, Director of RSCM/RS Soetomo, Head of the Ob/Gyn Department of FKUI/ FKUNAIR and the chairman of the POGI branch for Jakarta and East Java. Approximately 40 full or part time staff and trainers have been hired including administrators, physicians and midwives.

Initial functions of the NRC have been assigned, which include the following:

- finalization the National Resource Document (clinical family planning service delivery guidelines) as the primary guidelines for family planning services in Indonesia,

preparation of a practical clinical service guidelines handbook for service providers,

- preparation of training packages,

- preparation clinical trainers for PTCs,

- establishment of a critical mass of advanced trainers for disseminating CBT, and

- establishment of at least two model family planning service delivery clinics/training centers that model service delivery practices according to the national guidelines and employ CBT practices.

\section{NRC Service Delivery Sites Standardized}

two service delivery clinics have been identified, refurbished and their services standardized according to the national service delivery guidelines.

\section{NRC Service Delivery Sites Strengthened as Train- ing Sites}

clinical trainers at both NRC service delivery/training sites have completed training in clinical training skills, and will soon complete àn advanced training skills course.

\section{PTC Site Preparation}

The 27 PTC Sites have begun to take part in the same two step process of service delivery standardization and clinical training skill standardization as was applied to the NRC sites.

\section{Expanding the Clinical Training Network}

Indonesia has established a core group of reproductive health experts capable of greatly expanding the use of
CBT within medical and midwifery education and training. We must build upon this foundation in several ways:

- Success in creating a unified clinical training network, which employs CBT and which serves the clinical training needs of pre- and inservice programs for clinical family planning training, must be extended to other levels of the training clinical training network (i.e., remaining PTCs and DTCs) and to other topical areas of reproductive health important for securing further reductions in maternal mortality.

- The NRC which has a capacity to design and prepare standardized training packages consistent with CBT, must begin to apply this capacity to other specific family planning courses, both basic and refresher courses and must identify specific types of courses which would be most relevant for physicians and midwives in the area of essential obstetric care.

- The advanced trainer capacity of the NRC must be further tapped as a resource for strengthening the reproductive health component of preservice programs for physicians and midwives-thereby improving the quality of education of medical manpower. This has already begun in cooperation with the Consortium of Health Sciences (CHS).

- The NRC, in conjunction with Pusdiklat and other appropriate entities in DepKes, needs to form a joint collaboration to coordinate future activities. For example, now that CBT has proven itselt as an important method for ensuring that learners who complete a course can in fact demonstrate relevant skills and apply practical knowledge to clinical problems, we must:

- expand the use of CBT in all areas of reproductive health and even other areas of clinical medicine, and

- find alternative ways of implementing CBT. For example, innovative ways must be found for transferring the practical knowledge aspect of a CBT course-freeing it from an experience fixed in time and location. There must be decreasing dependence on trainers for knowledge transfer and more use made of "self- paced" experiences for learners.

Our success in expanding use of CBT and finding and implementing alternatives for implementing CBT will determine whether or not we are eventually successful in providing sufficient clinical skills training (both in pre- and inservice setting) to the staggering numbers of practitioners who need this training. The most 
dramatic example of this point is that currently there are 50,000 midwives who have already become (or are soon to become) village-based midwives. These practitioners are in need of a significant amount of inservice training in clinical skills and associated practical knowledge if they are to fulfill the government's desire to have them be effective reproductive health practitioners there.

\section{SUMMARY}

Viewed from the process of formation of a unified clinical training network and the successes achieved to date, we are accomplishing and can expect to make further progress in improving the availability of and access to quality reproductive health services throughout Indonesia. The activities completed to date can be seen as a model on first step in the realization of a dream; that is, to achieve for our nation a sustainable and high-level of health for all.

\section{REFERENCES}

1. Fathalla MF, Rosenfield A, Indriso C, Sen DK, Ratnam SS. "Reproduction Health, Global Issues" in the FIGO Manual of Human Reproduction, Volume 3. Parthenon: Lancs-New Jersey, 1990

2. Programme of Action of the United Nations International Conference on Population and Development, 1994

3. BKKBN, POGI, JHPIEGO. IUD and Norplant Training Assessment. Jakarta: BKKBN, 1992

4. POGI-JHPIEGO. Strengthening the Clinical Practice Training Network to Increase the Availability of Long Contraceptive Method Services in Indonesia. Jakarta: BKKBN, 1993

5. Saifuddin AB, Affandi B, Djajadilaga. IUD and Implant Training for Health Provider as an Effort to Improve Quality of Care of MKET. Jakarta: CHS \& BKKBN: 1993

6. Saifuddin AB, Djajadilaga, Affandi B. National Resource Document: Concept and Background in the Family Planning Framework. Jakarta: NRD Consultation Meeting, 1994 